\title{
Sobre metáfora, cognição, emoção e reframe: reflexões em tempos de pandemia
}

\author{
Suelen MARTINS (1) \\ Faculdade Arnaldo (Fajanssen)
}

\section{RESUMO}

Neste texto, resenham-se as considerações feitas por Filardo-Llamas et al. na mesa redonda Metáfora, cognición y emoción: reflexiones en tiempos de pandemia no evento virtual Abralin ao Vivo: Linguists Online. Na ocasião, as pesquisadoras apresentaram a iniciativa internacional, aberta e colaborativa \#ReframeCovid, projeto surgido a partir de conversas no Twitter entre linguistas da área cognitiva de vários países. Metodologicamente, as apresentadoras tomaram como referência o menu de metáforas para pessoas que vivem com câncer de Semino (2019), a fim de haver uma reflexão sobre os possíveis enquadres metafóricos acerca da pandemia de Covid19, com destaque para a utilização das metáforas bélicas, e de propor a discussão sobre enquadres alternativos àqueles relacionados à ideia de

OPEN ACCESS

EDITADO POR

Raquel Freitag

AVALIADO POR Paulo Henrique Duque

DATAS

Recebido: 03/08/2020 Aceito: 12/10/2020 Publicado: 21/10/2020

COMO CITAR

Martins, S. (2020).

Sobre metáfora, cognição, emoção e reframe: reflexões em tempos de pandemia. Revista da Abralin, v. 19, n. 2, p. 1-5, 2020. guerra. Filardo-Llamas et al. debateram os consequentes efeitos emocionais negativos causados pelas metáforas bélicas usadas em textos de diversos gêneros, principalmente, nos multimodais.

\section{ABSTRACT}

In this text, the considerations made by Filardo-Llamas et al. at the round table Metaphor, cognition and emotion: reflections in times of pandemic at the virtual event Abralin ao Vivo: Linguists Online. On the occasion, the researchers presented the international, open and collaborative initiative \#ReframeCovid, a project that emerged from conversations on Twitter between cognitive linguists from several countries. Methodologically, the presenters used as reference the menu of metaphors for people living with Semino's cancer (2019), in order to reflect on the possible metaphorical frameworks about the Covid-19 pandemic, with emphasis on the use of war metaphors, and to propose the discussion on alternative frameworks 


\section{REVISTA DA ABRALIN}

to those related to the idea of war. Filardo-Llamas et al. discussed the consequent negative emotional effects caused by the warlike metaphors used in texts of different genres, mainly in multimodals.

\section{PALAVRAS-CHAVE}

Metáforas. Cognição. Emoção.

\section{KEYWORDS}

Metaphor. Cognition. Emotion.

A mesa redonda Metáfora, cognición y emoción: reflexiones en tiempos de pandemia foi ministrada por Laura Filardo-Llamas, Iraide Ibarretxe-Antuñano, Reyes Llopis-García, Paula Pérez-Sobrino e Inés Olza, pesquisadoras da área de linguística cognitiva, com ênfase em metáfora e multimodalidade. A mesa foi apresentada em formato de conversa em que cada palestrante assumiu um turno no processo comunicativo. O objetivo da mesa foi apresentar as considerações acerca da anatomia do projeto \#ReframeCovid, uma iniciativa internacional, aberta e colaborativa cujo objetivo é refletir sobre os enquadres metafóricos relacionados ao contexto de pandemia da Covid-19 e sobre as possíveis metáforas alternativas (esportiva ou tsunami, por exemplo) às bélicas, comumente utilizadas para conceptualizar doenças. Segundo as pesquisadoras, tudo começou com uma conversa informal e contínua entre linguistas e cidadãos do mundo inteiro via Twitter. A primeira mensagem foi enviada por Inés Olza em que ela instigou o debate sobre metáforas de guerra e propôs um menu de metáforas alternativas àquelas bélicas, tendo como referência metodológica o menu de metáforas para pacientes que possuem com câncer de Semino (2019).

Os textos explorados pelas autoras são de natureza multimodal, especialidade das membras da mesa. Foram analisados cartazes com apelos bélicos, propagandas de empresas, vídeos e gestos. O primeiro texto apresentado como mote da discussão foi um vídeo, contendo a fala do presidente francês, Emmanuel Macron, sobre o isolamento social e a respeito de uma guerra travada contra um inimigo invisível e inalcançável. Essa visão foi reforçada com a exibição do vídeo do presidente dos Estados Unidos, Donald Trump, em que ele se intitulava um presidente em tempo de guerra e citava o vírus como um inimigo invisível. Fica, dessa forma, evidenciada a metáfora de guerra no discurso dos chefes de Estado, como apelo político, para se referir a essa emergência sanitária, a Covid-19, e suas consequências negativas à sociedade. Sendo assim, Olza reforçou a proposição de se repensar essa metáfora, já que, para elas, esta seria um mecanismo linguístico passível de suscitar emoções como medo e senso de responsabilidade concomitantemente.

A partir disso, as autoras lançaram a seguinte pergunta-chave do projeto: Por que se recorre frequentemente ao marco bélico para se referir à pandemia? Para Ibarretxe-Antuñano, tratava-se de uma ocorrência no mundo ocidental, observada na Espanha, no Brasil e nos Estados Unidos, por 


\section{REVISTA DA ABRALIN}

exemplo, justificada, em grande quantidade de textos de diferentes modalidades, mesmo que a maioria de nós não tenhamos vivenciado uma guerra, pelo fato de essas metáforas serem alicerçadas em nossa base experiencial e no nosso conhecimento sobre o que é uma guerra. Essas metáforas bélicas nos uniriam contra um inimigo comum. Nesse momento, Ibarretxe-Antunano mostrou o conceito de metáfora como uma janela do pensamento (conceito recorrente) em contraposição ao de figura de linguagem (conceito tradicional) como se a metáfora fosse um recurso ornamental. Dessa maneira, essa pesquisadora coadunou com Lakoff e Johnson (2003 [1980], p. 46, tradução nossa ${ }^{1}$ ). que, na obra Metaphors we live by (Metáforas da vida cotidiana), afirmam "[...] que as metáforas estruturam parcialmente nossos conceitos cotidianos e que essa estrutura se reflete em nossa linguagem literal". Ficou subjacente ao exposto que a noção de metáfora adotada foi a conceptual, cotidiana, aquela que ajuda na transmissão do conhecimento.

Reyes apresentou um vídeo, com a experiência de um profissional da área de saúde, e tematizou as consequências negativas de se usar e se abusar das metáforas bélicas. Segundo o relato, motivado pela pergunta "como se sente um herói"?, ficou evidente que nem sempre esses profissionais aprovavam a imagem de heróis, de soldados e de um exército de salvamento. No vídeo, o fisioterapeuta e ortopedista afirmou que entre os profissionais não havia sargentos, nem generais, tampouco soldados contra o vírus, pois todos estavam trabalhando. Sendo assim, a partir da fala do entrevistado, ficou evidente para nós que nem todos os elementos do domínio-fonte GUERRA são projetados no domínioalvo PANDEMIA, o que corrobora Lakoff (2006) que afirma que não se deve pensar em mapeamento como processos algorítmicos iniciados pelo domínio-fonte e terminados pelo domínio-alvo.

Apesar da grande relevância do projeto e de sua significativa abrangência, precisamos refletir sobre dois aspectos que envolvem o trabalho apresentado: a sugestão de um reframe e a tentativa de construir um menu de metáfora. Mesmo com a exposição de tantos textos de gêneros diversos e com seus respectivos debates, a sensação é a de que restaram para o interlocutor algumas arestas não aparadas e a pergunta de como as pesquisadoras conseguiram resolver essas duas questões que são, dentro das discussões da Linguística Cognitiva, por vezes, controversas. Acreditamos, no entanto, que os limites temporais impostos a uma apresentação em mesa redonda possam impedir maiores esclarecimentos acerca dessas questões.

Em primeiro lugar, precisamos entender que os "frames são estruturas mentais que moldam a maneira como vemos o mundo. Como resultado, eles moldam os objetivos que traçamos, os planos que fazemos, a maneira como agimos e o que conta como resultados bons ou ruins de nossa ação" (LAKOFF, 2004, p. xv, tradução nossa ${ }^{2}$ ). A lógica dos frames descreve significados, tendo como fundamento todo um sistema de categorias prototípicas formadas a partir do contexto em que o sujeito se encontra e experimenta as coisas do mundo. O processo de reframe, por outra via, envolve, então,

1 No original: "that metaphors partially structure our everyday concepts and that this structure is reflected in our literal language".

2 No original: "frames are mental structures that shape the way we see the world. As a result, they shape the goals and seek, the plans we make, the way we act, and what counts as a good or bad outcome of our actions". 


\section{REVISTA DA ABRALIN}

uma mudança desses frames e, por extensão, a alteração do significado de uma dada realidade, quer dizer, uma mudança social.

Sendo assim, ao proporem que haja um reframe de Covid, as autoras sugerem que aconteça uma modificação do enquadre, quer dizer, que não se pense em Covid-19 a partir da conceptualização bélica, e, consequentemente, ocorra a mudança de significação sobre a pandemia e dos efeitos emocionais causados pelo uso desse enquadre negativo. Assim, as emoções de medo, de pânico e de ansiedade poderiam ser ressignificadas. Resta-nos, a partir dessas afirmações, os seguintes questionamentos: seria possível, de fato, com o reframing de Covid-19, mudar realidades e efeitos? quais os critérios para se eliminar uma metáfora em detrimento de outras para se referir à Covid-19? Faltou às pesquisadoras, ao todo da explanação, realizar essas ponderações.

Em segundo lugar, faz-se necessário compreender a lógica do menu de metáfora de Semino (2019). A proposta desse menu é recomendar que os médicos e a mídia evitem tratar a doença como uma batalha, pois essa metáfora tem consequências, demasiadamente, negativas nos pacientes, em fase terminal, os quais se sentem desencorajados. Quanto à pandemia de Covid-19, as metáforas bélicas seriam negativas e retumbariam nas redes sociais também de forma ruim. Para o interlocutor da mesa redonda, faltou posicionamento mais claro em prol da metáfora situada que, segundo Vereza (2016), faz parte da tessitura do texto, é deliberada e estaria associada aos frames on-line e a eventos episódicos (discursivos). Desse modo, restam-nos duas perguntas: a sociedade conseguiria, ao mencionar a pandemia e seus milhares de mortos, forjar facilmente outras metáforas senão aquelas relacionadas a uma guerra?; qual metodologia adotada para afirmar os efeitos negativos das metáforas bélicas em tempos de pandemia? Parece-nos que, na mesa redonda, apenas as metáforas conceptuais, aquelas de um nível mais estável, foram convocadas para a análise dos materiais recebidos pelo projeto \#ReframeCovid. Parece-nos que sugerir um menu de metáforas engessaria a espontaneidade da comunicação e a emergência das metáforas no discurso. Sendo assim, resolver essa questão tem relação com a proposição de um reframe para a Covid-19.

Por fim, um ponto alto da mesa redonda foi que as pesquisadoras assumiram uma metodologia de dados abertos para que outros projetos pudessem surgir a partir da iniciativa delas. Isso demonstra grande generosidade por parte de Filardo-Llamas et al. ao partilharem os conteúdos e reforça ainda mais o caráter internacional e colaborativo mencionado no evento virtual. Como a priori, as linguistas não delimitaram objetivos ou hipóteses, uma vez que a motivação delas era entender como as metáforas de Covid-19 são apresentadas e quais seus efeitos negativos, colocar os dados abertos pode gerar pesquisas com diferentes intenções e hipóteses diversas, num processo de aperfeiçoamento e completude do que cuidadosamente já está sendo realizado.

\section{REFERÊNCIAS}

LAKOFF, G. Don't think of an Elephant!: Know your values and frame the debate. Vermont: Chelsea Green Publishing, 2004. 


\section{REVISTA DA ABRALIN}

LAKOFF, G. The contemporary theory of metaphor. In: GEERAERTS, D. Cognitive linguistics: basic readings. Berlin: Mouton de Gruyter, 2006 [1993], p. 185-239. DOI: https://doi.org/10.1515/9783110199901

LAKOFF, G; JOHNSON, M. Metaphors we live by. Chicago: The University of Chicago Press, 2003 [1980]. DOI: Https://doi.org/10.7208/chicago/9780226470993.001.0001

METÁFORA, cognición y emoción: reflexiones en tiempos de pandemia. Mesa redonda apresentada por Laura Filardo-Llamas et.al. [s.l., s.n], 2020. 1 vídeo (2h 03min 00s). Publicada pelo canal da Associação Brasileira de Linguística. Disponível em: https://youtu.be/MBsPqwGjllM. Acesso em: 31 jul. 2020.

SEMINO, E. A metaphor menu for people living with cancer. Lancaster: Lancaster University, 2019.

VEREZA, S. C. Cognição e sociedade: um olhar sob a ótica da linguística cognitiva. Linguagem em (Dis)curso - LemD, Tubarão, v.16, n.3, p. 561-573, set./dez.2016. DOI: http://dx.doi.org/10.1590/1982-4017-160303-0416D15 